Carbohydrate Research, 61 (1978) 129-138

(C) Elsevier Scientific Publishing Company, Amsterdam - Printed in The Netherlands

\title{
EQUILIBRIUM DIALYSIS AND CARBOHYDRATE-BINDING STUDIES ON THE 2-ACETAMIDO-2-DEOXY-D-GLUCOPYRANOSYL-BINDING LECTIN FROM Bandeiraea simplicifolia SEEDS*
}

Shigeyuki Ebisu, P. N. Shankar Iyer, and Irwin J. Goldstein

Department of Biological Chemistry, The University of Michigan, Ann Arbor, Michigan 48109 (U.S.A.)

(Received July 5th, 1977; accepted for publication, October 14th, 1977)

ABSTRACT

The carbohydrate-binding specificity of Bandeiraea simplicifolia lectin II (BS II lectin) has been studied by quantitative precipitin and hapten-inhibition analysis. The BS II lectin precipitated biopolymers having nonreducing 2-acetamido2-deoxy-D-glucopyranosyl residues, such as antigen A. Dextran B-1355-S and rabbitliver glycogen also afforded precipitin curves with high concentrations of the BS II lectin. Phenyl 2-acetamido-2-deoxy- $\alpha$-D-glucopyranoside and $p$-nitrophenyl 2acetamido-2-deoxy- $\alpha$-D-glucopyranoside, the best inhibitors of the BS II lectin-pazophenyl 2-acetamido-2-deoxy- $\beta$-D-glucopyranoside-bovine serum albumin conjugate precipitin-system, were 4 times as active as 2-acetamido-2-deoxy-D-glucopyranose. Of the free monosaccharides tested, 2-acetamido-2-deoxy-D-glucopyranose was the most potent inhibitor, being over 100 times better than D-fructose and 400 times better than D-glucose. Comparison of the inhibiting capacity of methyl or p-nitrophenyl 2-acetamido-2-deoxy- $\alpha$-D-glucopyranoside with their corresponding $\beta$ anomers showed that the $\alpha$ anomer was bound 6 to 8 times more avidly than the $\beta$ anomer. Replacement of the C-3, C-4, or C-6 hydroxyl group of D-glucose by a methoxyl group or a fluorine atom abolished the capacity of the resulting sugar to bind the BS II lectin, but substitution of the C-2 hydroxyl group of D-glucose, by either a methoxyl group or a fluorine group, had no appreciable effect on binding to the lectin. $N, N^{\prime}$-Diacetylchitobiose was as active as $N, N^{\prime}, N^{\prime \prime}$-triacetylchitotriose, and they were both twice as potent as disaccharides having a nonreducing 2-acetamido2-deoxy- $\alpha$-D-glucopyranosyl residue. Disaccharides having $\beta$-D-(1 $\rightarrow 6)$ glycosidic bonds were very poor inhibitors. Equilibrium-dialysis experiments with $p$-nitrophenyl 2-acetamido-2-deoxy- $\alpha$-D-glucopyranoside as binding ligand indicated that the BS II lectin possesses approximately one carbohydrate-binding site per subunit for the tetrameric protein $\left(M_{r} 113,000\right)$, with association constants of $1.3 \times 10^{5} M^{-1}$ at $4^{\circ}$, and $0.4 \times 10^{5} M^{-1}$ at $37^{\circ}$.

*Dedicated to Professor Dexter French on the occasion of his 60th birthday. 
INTRODUCTION

Extracts of Bandeiraea simplicifolia seeds have been shown to contain two lectins having different carbohydrate-binding specificities: an $\alpha-D$-galactopyranosylbinding lectin ${ }^{1}$ (designated BS I lectin) and a 2-acetamido-2-deoxy- $\alpha$-and- $\beta$-Dglucopyranosyl-binding lectin ${ }^{2}$, designated BS II lectin. The BS I lectin was shown to consist of a family of five, tetrameric isolectins composed of two, distinctly different, subunits; the five isolectins were purified by affinity chromatography on matrices consisting of Bio-Gel-melibionate and insolubilized blood-group A substance ${ }^{3}$.

The BS II lectin, purified by affinity chromatography on chitin, is a glycoprotein composed of four similar subunits, of molecular weight approximately ${ }^{2} 30,000$. The BS II lectin does not agglutinate human type $\mathrm{A}, \mathrm{B}$, or $\mathrm{O}$ erythrocytes ${ }^{2}$, but reacts with acquired-B, T-activated, and Tk polyagglutinable cells ${ }^{4}$. It gave precipitin-like curves with $p$-azophenyl 2-acetamido-2-deoxy- $\alpha$-and- $\beta$-D-glucopyranoside-bovine serum albumin conjugates ${ }^{2}$, and also afforded precipitin curves with certain bloodgroup substances containing terminal nonreducing 2 -acetamido-2-deoxy- $\alpha$-D-glucopyranosyl residues 5 .

Detailed studies on the molecular properties and the carbohydrate-binding specificity of the BS II lectin have been carried out in our laboratory and will be published in due course. In the present paper, we describe the carbohydrate-binding specificity of the BS II lectin and the results of equilibrium-dialysis experiments with $p$-nitrophenyl 2-acetamido-2-deoxy- $\alpha$-D-glucopyranoside as binding ligand.

\section{MATERIALS AND METHODS}

Most of the carbohydrates used in this work were available from previous studies $^{2,6}$.

$N$-Acetyl-lactosamine was a gift from Dr. G. W. Jourdian (University of Michigan, Ann Arbor, Michigan, U.S.A.). Soluble peptidoglycan from Lactobacillus plantarum and 2-acetamido-4-O-(2-acetamido-2-deoxy- $\beta$-D-glucopyranosyl)-3-O-(1carboxyethyl)-2-deoxy-D-glucopyranose were gifts from Dr. K. Kato (Osaka University, Osaka, Japan); 3-O-(2-acetamido-2-deoxy- $\beta$-D-glucopyranosyl)-D-galactopyranose and 6-O-(2-acetamido-2-deoxy- $\beta$-D-glucopyranosyl)-D-galactopyranose were gifts from Dr. Z. Yosizawa (Tohoku University, Sendai, Japan); 3,6-di-O-(2-acetamido2-deoxy- $\boldsymbol{\beta}$-D-glucopyranosyl)-D-galactopyranose was a gift from Dr. S. David (University of Paris, Orsay, France). Antigen A was a gift from Dr. T. W. Shier (Salk Institute, San Diego, Calif., U.S.A.). $\beta$-D-Glucan of Sclerotium rolfsii was a gift from Dr. S. Kirkwood (University of Minnesota, St. Paul, Minn., U.S.A.).

BS II lectin was purified from seed extract by affinity chromatography on chitin as described previously 2,7 .

Protein was determined by the method of Janatova et al. ${ }^{8}$, with bovine serum albumin as standard.

Quantitative precipitin-analyses and inhibition studies were carried out by the 
modified procedure described by So and Goldstein ${ }^{9}$ in a final volume of $500 \mu \mathrm{l}$; $175 \mu \mathrm{g}$ of the lectin was used in each tube unless otherwise noted. The tubes were incubated for $1 \mathrm{~h}$ at $37^{\circ}$ and then for 2 days at $4^{\circ}$. The tubes were centrifuged; nitrogen in the washed precipitates was determined by the ninhydrin method ${ }^{10}$, and protein by a semimicro Lowry procedure ${ }^{11}$.

Equilibrium-dialysis experiments were performed in Karush-type cells ${ }^{12}$ with $1.0 \mathrm{ml}$ of the BS II lectin solution in phosphate-buffered saline $(0.1 \mathrm{M}$ phosphate, pH 7.0, $0.15 \mathrm{~m}$ sodium chloride, $0.04 \%$ sodium azide, $0.1 \mathrm{~mm}$ calcium chloride, $0.1 \mathrm{~mm}$ magnesium chloride, and $0.1 \mathrm{~mm}$ manganous chloride) and $1.0 \mathrm{ml}$ of the ligand solution in phosphate-buffered saline on one side of the cellulose membrane, and $1.0 \mathrm{ml}$ of the ligand solution and $1.0 \mathrm{ml}$ of phosphate-buffered saline on the other side. $p$ Nitrophenyl 2-acetamido-2-deoxy- $\alpha$-D-glucopyranoside was employed as ligand. Filled cells were rotated slowly on a multipurpose rotator for $24 \mathrm{~h}$ at $4^{\circ}$ or at $37^{\circ}$. Concentrations of $p$-nitrophenyl 2-acetamido-2-deoxy- $\alpha$-D-glucopyranoside were determined spectrophotometrically from the absorbance of solutions of this compound at $305 \mathrm{~nm}$ by using a molar absorptivity of $10,000 \mathrm{~cm}^{-1} \mathrm{M}^{-1}$ at $\mathrm{pH} 7.0$ (ref. 13). The extent of binding was calculated from the amounts of ligand added and the concentration of free ligand at equilibrium, as described by Loontiens et al. ${ }^{14}$

RESULTS

Quantitative precipitation studies. - A number of biopolymers containing either terminal and/or internal 2-acetamido-2-deoxy-D-glucopyranosyl residue(s) were examined for their capacity to form a precipitate with the BS II lectin. These included Shier's antigen $\mathrm{A}$, which is an $N, N^{\prime}$-diacetylchitobiosyl-poly(L-aspartate) polymer ${ }^{15}$, carcinoembryonic antigen (CEA) and pncumococcal S-14 polysaccharide (which contain internal 2 -acetamido-2-deoxy- $\beta$-D-glucopyranosyl residues ${ }^{16,17}$, soluble peptidoglycan $^{18}$ from Lactobacillus plantarum (which possesses a chain consisting of alternating 2-acetamido-2-deoxy- $\beta$-D-glucopyranosyl and 2-acetamido-3-O-(1-carboxyethyl)-2-deoxy- $\beta$-D-glucopyranosyl residues), fetuin (which contains internal 2 -acetamido-2-deoxy- $\beta$-D-glucopyranosyl residues) ${ }^{19}$, and hyaluronic acid (which consists of alternating $\beta$-D-glucopyranosyluronic acid and 2-acetamido-2-deoxy- $\beta$-Dglucopyranosyl residues). Of these substrates, only antigen A precipitated the BS II lectin. (Wheat-germ agglutinin precipitated all substrates except hyaluronic acid ${ }^{20-23}$.) At the point of maximum precipitation, $30 \mu \mathrm{g}$ of antigen A precipitated $83 \%$ of the lectin added.

The quantitative precipitin-reactions of the BS II lectin with some polysaccharides are shown in Fig. 1. As the standard concentration of the BS II lectin (175 $\mu \mathrm{g}$ per tube) employed did not give significant amounts of precipitate, a higher concentration of lectin (540 $\mu \mathrm{g}$ per tube) was used. Rabbit-liver glycogen and dextran B-1355-S precipitated approximately $14 \%$ of the lectin N added; the mannan of Saccharomyces cerevisiae precipitated only $5.5 \%$; and dextran B-512, the levan of Aerobacter levanicum, 


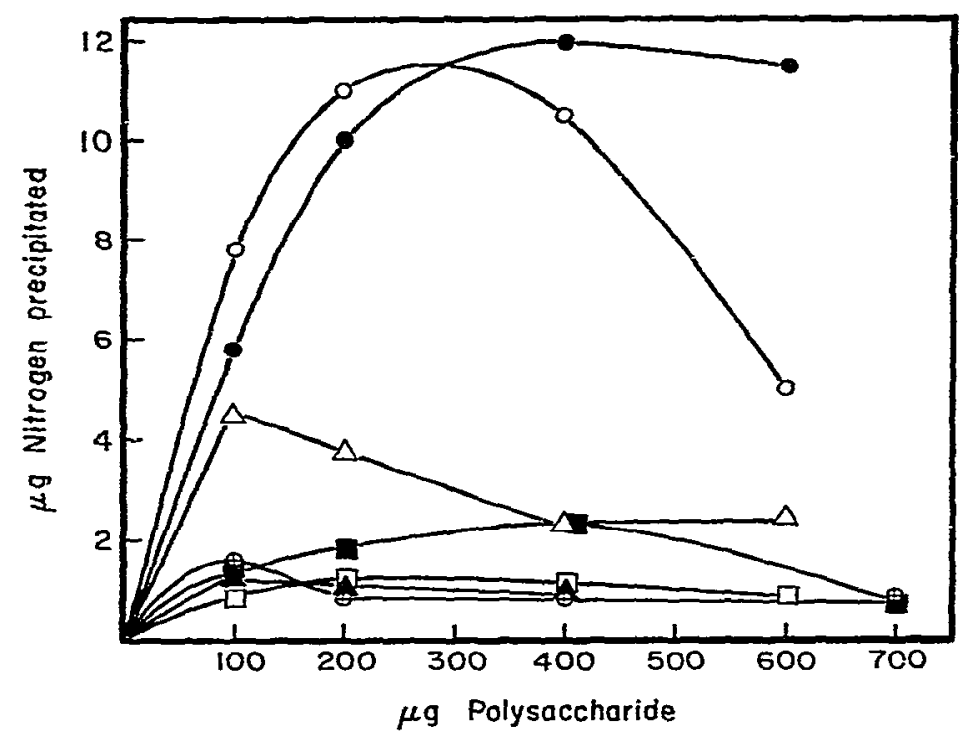

Fig. 1. Quantitative precipitin-curves of the BS II lectin with some polysaccharides. Each tube contained $540 \mu \mathrm{g}$ of the lectin and increasing amounts of polysaccharide in a total volume of $500 \mu 1$. $O$, Dextran B-1355-S; $\bullet$, rabbit-liver glycogen; $\triangle$. mannan from Saccharomyces cerevisiae; $\boldsymbol{A}$, levan from Aerobacter levanicum; $\square$, dextran B-512;,$\beta$-D-glucan from Sclerotium rolfsii; and $\oplus$, poly(2-deoxy-D-arabino-hexose).

\section{TABLE I}

INHIBITION OF THE BS II LECTIN-p-AZOPHENYL 2-ACETAMIDO-2-DEOXY- $\beta$-D-GLUCOPYRANOSIDE-BOVINE SERUM ALBUMIN CONJUGATE PRECIPITIN-REACTTON BY AMINO SUGARS AND THEIR DERIVATIVES

Sugar

Inhibitor concentration (nmol) required for $50 \%$ inhibition

2-Acetamido-2-deoxy-D-glucopyranose

2-Acetamido-2-deoxy-D-mannopyranose

2-Acetamido-2-deoxy-D-galactopyranose

Methyl 2-acetamido-2-deoxy- $\alpha$-D-glucopyranoside

Methyl 2-acetamido-2-deoxy- $\beta$-D-glucopyranoside

Methyl 2-(bromoacetamido)-2-deoxy- $\beta$-D-glucopyranoside

$p$-Nitrophenyl 2-acetamido-2-deoxy- $\alpha$-D-glucopyranoside

$p$-Nitrophenyl 2-acetamido-2-deoxy- $\beta$-D-glucopyranoside

Methyl 2-deoxy-2-( $p$-nitrobenzamido)- $\alpha$-D-glucopyranoside

Methyl 2-deoxy-2-( $p$-nitrobenzamido)- $\beta$-D-glucopyranoside

Ethyl 2-acetamido-2-deoxy- $\alpha$-D-glucopyranoside

Phenyl 2-acetamido-2-deoxy- $\alpha$-D-glucopyranoside

2-Deoxy-2-formamido-D-glucopyranose

2-Amino-2-deoxy-D-glucopyranose

2-Acetamido-3-0-(1-carboxyethyl)-2-deoxy-D-glucopyranose

-

17,000

$0 \%$ at $50,000^{a, b}$

$10^{a}$

$80^{\circ}$

71

56

$30^{\circ}$

7

57

6

3

52

1,500

$1 \%$ at $10,000^{b}$

${ }^{a}$ From ref. 2. ${ }^{b}$ Indicates the percentage inhibition for the nmol of inhibitor noted. 
the $\beta$-glucan of Sclerotium rolfsii, and a poly(2-deoxy-D-arabino-hexose) ${ }^{24}$ were essentially inactive.

Hapten-inhibition studies. - The specificity of the BS II lectin-binding site was probed by sugar inhibition of the BS II lectin-p-azophenyl 2-acetamido-2-deoxy$\beta$-D-glucopyranoside-bovine serum albumin conjugate-precipitating system.

Table I compares the amount of three amino sugars and their derivatives required for $50 \%$ inhibition of the precipitating system. Only 2-acetamido-2-deoxyD-glucopyranose was a potent inhibitor. Comparison of the methyl and $p$-nitrophenyl $\alpha$ - and $\beta$-glycosides of 2-acetamido-2-deoxy-D-glucopyranose indicated that the $\alpha$ anomer was bound six to eight times more avidly than the corresponding $\beta$ anomer. Phenyl 2-acetamido-2-deoxy- $\alpha$-D-glucopyranoside was approximately 3 times more potent an inhibitor than the corresponding methyl glucoside. It is noteworthy that, unlike the lima-bean lectin ${ }^{25}$, addition of an aromatic moiety ( $p$-nitrobenzoyl or a bromoacetyl group) to the C-2 amino group had no appreciable effect on inhibitory activity in the BS II system.

Replacement of the acetyl group of 2-acetamido-2-deoxy-D-glucopyranose by a formyl group produced a 3-fold decrease in the inhibiting potency. Free 2-amino-2deoxy-D-glucopyranose is 100 times less inhibitory than the $N$-acetylated amino

\section{TABLE II}

INHIBITION OF THE BS $\Pi$ LECTIN-p-AZOPHENYL, 2-ACETAMIDO-2-DEOXY- $\beta$-D-GLUCOPYRANOSIDE-BOVINE SERUM ALBUMIN CONJUGATE PRECIPITIN-REACTION BY SOME HEXOSES AND THEIR DERIVATIVES

Sugar

Inhibitor concentration (nmol) required

for $50 \%$ inhibition

D-Glucose

Methyl $\alpha$-D-glucopyranoside

Methyl $\beta$-D-glucopyranoside

$p$-Nitrophenyl $\beta$-D-glucopyranoside

2- $O$-Methyl-D-glucopyranose

3-O-Methyl-D-glucopyranose

Methyl 4-O-methyl- $\alpha-D$-glucopyranoside

Methyl 2-deoxy- $\alpha$-D-arabino-hexopyranoside

Methyl 6-deoxy- $\beta$-D-glucopyranoside

$\alpha$-D-Glucopyranosyl fiuoride

3-Deoxy-3-fluoro-D-glucopyranose

4-Deoxy-4-fluoro-D-glucopyranoside

Methyl 6-deoxy-6-fiuoro- $\alpha$-D-glucopyranoside

1,5-Anhydro-D-glucitol

Methyl $\alpha-D-$ mannopyranoside

Methyl $\alpha$-D-galactopyranoside

D-Fructose

Methyl $\alpha$-D-fructofuranoside

Methyl $\beta$-D-fructofuranoside

Methyl $\beta$-D-fructopyranoside

$\begin{array}{cc} & 7,400^{a} \\ & 1,300^{a} \\ & 16,000^{a} \\ & 7,000 \\ & 2,500 \\ 0 \% \text { at } & 20,000^{\circ} \\ 0 \% \text { at } & 30,000^{b} \\ & 2,300 \\ 4 \% \text { at } & 30,000^{b} \\ & 1,500 \\ 11.2 \% \text { at } & 10,000^{b} \\ 20 \% \text { at } & 10,000^{b} \\ 14 \% \text { at } & 10,000^{b} \\ & 2,100 \\ & 1,800 \\ 0 \% \text { at } 100,000^{a, b} \\ \\ & 1,900 \\ 0 \% \text { at } & 5,000^{b} \\ 0 \% \text { at } & 5,000^{b} \\ \text {. } & 2,100\end{array}$

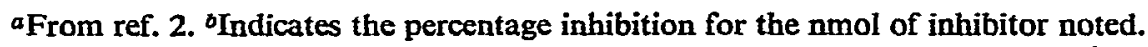


sugar. Replacement of the C-3 hydroxyl group by a lactyl group (as in $\mathrm{N}$-acetylmuramic acid) completely abolished binding.

As shown in Table II, several derivatives of D-glucose were tested in order to define which functional groups in the carbohydrate ligand are involved in binding to the BS II lectin. D-Glucose was approximately 400 times less effective an inhibitor than 2-acetamido-2-deoxy-D-glucopyranose. Methyl $\alpha$-D-glucopyranoside was approximately 10 times more potent than the $\beta$-glycoside. Replacement of the $\mathrm{C}-3, \mathrm{C}-4$, or C-6 hydroxyl group of $\mathrm{D}$-glucose by a methoxyl group or a fluorine atom abolished the capacity of the resulting sugar to bind to the BS II lectin, whereas substitution of the C-2 hydroxyl group, either by a methoxyl or a fluorine group, showed no appreciable effect on binding. Methyl $\alpha$-D-glucopyranoside was 1.6 times more effective an inhibitor than the analogous compound (1,5-anhydro-D-glucitol) lacking the C-1 methoxyl group, but an 8-fold decrease in the inhibiting activity of this compound was observed by the introduction of a $\beta$-disposed $1-O$-methyl group (in methyl $\beta$-D-glucopyranoside).

D-Fructose was 4 times more potent an inhibitor than D-glucose. Of the methyl glycosides of D-fructose, methyl $\beta$-D-fructopyranoside was found to be an inhibitor

\section{TABLE III}

INHIBITION OF THE BS II LECTIN- $p$-AZOPHENYL 2-ACETAMIDO-2-DEOXY- $\beta$-D-GLUCOPYRANOSIDE-BOVINE SERUM ALBUMIN CONJUGATE PRECIPITIN-REACTION BY OLIGOSACCHARIDES CONTAINING 2-ACETAMIDO2-DEOXY-D-GLUCOSE

Sugar

Inhibitor concentration (nmol) required for $50 \%$ inhibition

$N, N^{\prime}$-Diacetylchitobiose $[\beta$-D-GlcNAC- $(1 \rightarrow 4)$-D-GlcNAc]

$N, N^{\prime}, N^{\prime \prime}$-Triacetylchitotriose

$[\beta$-D-GICNAC- $(1 \rightarrow 4)-\beta$-D-GICNAC- $(1 \rightarrow 4)-D-G I C N A c]$

3-O-(2-Acetamido-2-deoxy- $\alpha$-D-glucopyranosyl)-D-glucopyranose $\quad 106$ [ $\alpha$-D-GICNAC-(1 $\rightarrow 3)-D-G I C]$

3- $O$-(2-Acetamido-2-deoxy- $\beta$-D-glucopyranosy1)-n-galactopyranose 73

$[\beta$-D-GlcNAc- $(1 \rightarrow 3)-\mathrm{D}-\mathrm{Gal}]$

6-O-(2-Acetamido-2-deoxy- $\alpha$-D-glucopyranosyl)-D-galactopyranose $\quad 10$ $[\alpha-D-G l c N A c-(1 \rightarrow 6)-D-G a l]$

6-O-(2-Acetamido-2-deoxy- $\beta$-D-glucopyranosyl)-D-galactopyranose [ $\beta$-D-GleNAc- $(1 \rightarrow 6)$-D-Gal]

Methyl 2-O-(2-acetamido-2-deoxy- $\alpha$-D-glucopyranosyl)- $\alpha$-D-glucopyranoside

$[\alpha-D-G I c N A c-(1 \rightarrow 2)-M e-\alpha-D-G I c]$

2-Acetamido-4-O-(2-acetamido-2-deoxy- $\beta$-D-glucopyranosyl)-3-

$O$-(1-carboxyethyl)-2-deoxy-D-glucopyranose

$[\beta$-D-GlcNAC- $(1 \rightarrow 4)$-D-MurNAc]

2-Acetamido-2-deoxy-4-O-( $\beta$-D-galactosyl)-D-glucopyranose $[\beta$-D-Gal-(1 $\rightarrow 4)$-D-GIcNAc]

3,6-Di- $O$-(2-acetamido-2-deoxy- $\beta$-D-glucopyranosyl)-D-galactopyranose $[\beta$-D-GICNAC- $(1 \rightarrow 3)$ [ $\beta$-D-GlcNAc- $(1 \rightarrow 6)]-D-G a l]$

From ref. 2. 'Indicates the percentage inhibition for the nmol of inhibitor noted. 
of the BS II lectin-p-azophenyl 2-acetamido-2-deoxy- $\beta$-D-glucopyranoside-bovine serum albumin precipitation, whereas neither methyl $\alpha$ - nor $\beta$-D-fructofuranoside was inhibitory (compare ref. 26).

Several oligosaccharides containing 2-acetamido-2-deoxy-D-glucopyranosyl residues were examined for their capacity to inhibit the BS II lectin-p-azophenyl 2-acetamido-2-deoxy- $\beta$-D-glucopyranoside-bovine serum albumin interaction; these are listed in Table III. $N, N^{\prime}$-Diacetylchitobiose was equivalent to $N, N^{\prime}, N^{\prime \prime}$-triacetylchitotriose, and these chito-oligosaccharides, in turn, were 3 times more potent than 2-acetamido-2-deoxy-D-glucopyranose. Comparison of the inhibition potency of 6-O-(2-acetamido-2-deoxy- $\alpha-D$-glucopyranosyl)-D-galactopyranose with the respective $\beta$-D-linked disaccharide [6-O-(2-acetamido-2-deoxy- $\beta$-D-glucopyranosyl)-D-galactopyranose) indicated the $\alpha$-D-linked disaccharide to be 10 times more potent an inhibitor than the $\beta$-D-linked isomer. The same relationship was found to exist between methyl 2-acetamido-2-deoxy- $\alpha$ - and - $\beta$-D-glucopyranosides.

A synthetic trisaccharide [3,6-di- $O$-(2-acetamido-2-deoxy- $\beta$-D-glucopyranosyl)D-galactopyranose] having two, nonreducing 2-acetamido-2-deoxy- $\beta$-D-glucopyranosyl residues was as active an inhibitor as the disaccharide having a nonreducing 2-acetamido-2-deoxy- $\beta$-D-glucopyranosyl group. $N$-Acetyl-lactosamine, which has a 2-acetamido-2-deoxy-D-glucopyranose residue at the reducing position, was a non-inhibitor.

Several oligosaccharides having D-glucosyl residue(s) were also tested for their inhibitory activity and the results are presented in Table IV. Of the oligosaccharides containing D-glucosyl residue(s) tested, sucrose was the best inhibitor. All-D-glucosecontaining disaccharides showed similar inhibitory activity, except for gentiobiose, the $\beta$-D- $(I \rightarrow 6)$-linked glucobiose.

\section{TABLE IV}

INHIBITION OF THE BS II LECTIN-p-AZOPHENYL 2-ACETAMIDO-2-DEOXY- $\beta$-D-GLUCOPYRANOSIDE-BOVINE SERUM ALBUMIN CONJUGATE PRECIPITIN-REACTION BY OLIGOSACCHARIDES CONTAINING D-GLUCOSE

Sugar

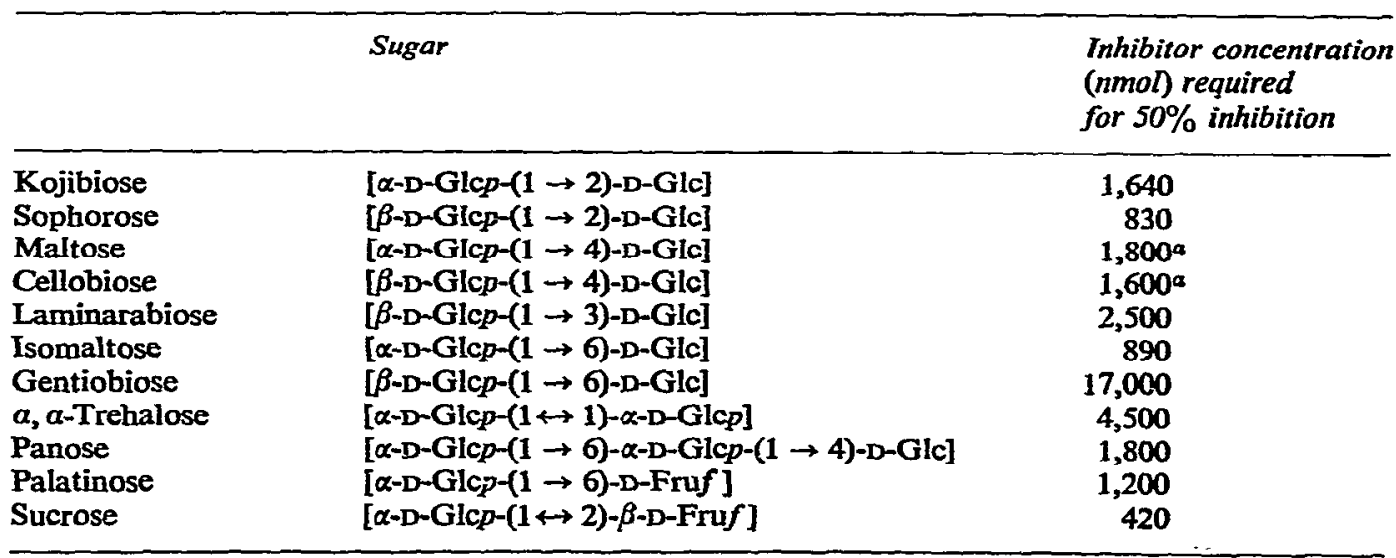

sFrom ref. 2 . 


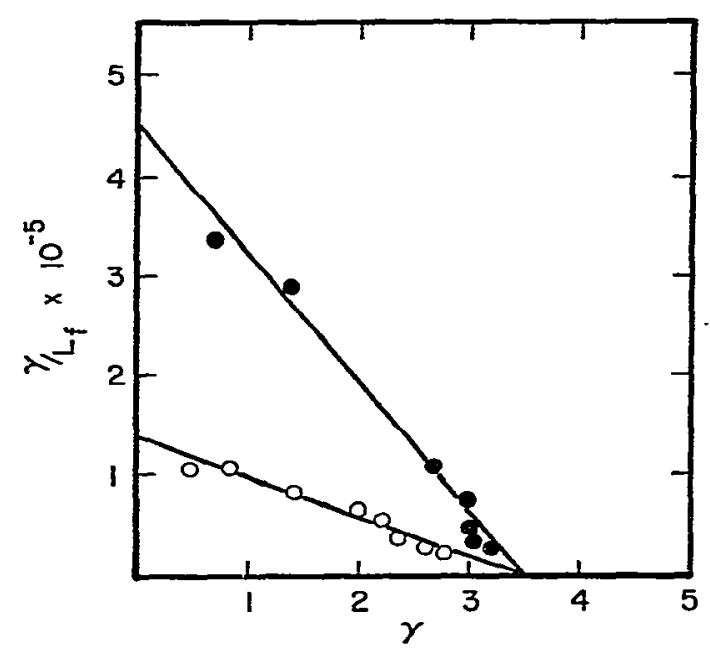

Fig. 2. Scatchard plots of the binding of $p$-nitrophenyl 2-acetamido-2-deoxy- $\alpha$-D-glucopyranoside to the BS II lectin: $r$, mol of sugar bound per mol of the lectin (molecular weight, 113,000 ); $L_{f}$, concentration of free ligand $\left(\theta, 4^{\circ} ; O, 37^{\circ}\right)$; protein concentration was $2.1 \mathrm{mg} / \mathrm{ml}$ in phosphate-buffered saline; initial ligand concentration varied from 5 to $125 \mu \mathrm{M}$ in phosphate-buffered saline. Experimental details are given in the text.

Equilibrium dialysis. - The binding of $p$-nitrophenyl 2-acetamido-2-deoxy- $\alpha$-Dglucopyranoside (a potent inhibitor of the BS II lectin-p-azophenyl 2-acetamido-2deoxy- $\beta$-D-glucopyranoside-bovine serum albumin precipitin-reaction) to the lectin was examined by equilibrium dialysis at $\mathrm{pH}$ 7.0. Scatchard plots of the results of the binding experiments are shown in Fig. 2. The number $(n)$ of independent binding sites and the association constant $(K)$ were calculated from the equation $r / L_{f}=$ $n K-r K$ (Ref. 27), in which $r$ is the number of mol of ligand bound per mol of protein, and $L_{f}$ is the concentration of free ligand at equilibrium. Linear plots were obtained at 4 and $37^{\circ}$, showing values of $r$ equal to 3.5. The calculated associationconstants are $1.3 \times 10^{5} \mathrm{M}^{-1}$ at $4^{\circ}$ and $0.4 \times 10^{5} \mathrm{M}^{-1}$ at $37^{\circ}$.

\section{DISCUSSION}

The present study extends the results of Shankar Iyer and coworkers ${ }^{2}$ and Wood and his colleagues ${ }^{5}$ regarding the carbohydrate-binding specificity of the BS II lectin, and adds the important information that this tetrameric, 2-acetamido-2-deoxyD-glucopyranose-binding lectin possesses essentially one binding site per subunit. The fact that the binding curves are linear suggests that the lectin's combining sites are independent and non-interacting. The association constant for BS II $\left(\sim 10^{5} \mathrm{M}^{-1}\right)$ is one of the highest reported for a lectin in its interaction with a ligand of low molecular weight.

Hapten-inhibition studies indicated that the BS II lectin possesses combining sites that are complementary to non-reducing, terminal 2-acetamido-2-deoxy-D- 
glucopyranosyl groups $\alpha$ - or $\beta$-D-linked to a second sugar. Binding is best when the reducing-sugar residue of a disaccharide has the D-gluco configuration.

In order to ascertain which hydroxyl group and/or $N$-acetyl groups of 2-acetamido-2-deoxy-D-glucopyranose are involved in binding to the lectin, we have employed deoxy-, $O$-methyl, and fluoro derivatives of $D$-glucose as hapten inhibitors. The results of our study underscore the necessity for an unmodified 2-acetamido-2-deoxy-Dglucopyranosyl group. An axial 2-acetamido-2-deoxy group (2-acetamido-2-deoxy-Dmannopyranose) or an axial C-4 hydroxyl group (2-acetamido-2-deoxy-D-galactopyranose) essentially abolish binding to the lectin. As is the case for concanavalin $\mathrm{A}$ (ref. 28), alterations at C-3, C-4, or C-6 of the sugar ring also abolish binding activity to BS II.

Our results suggest the participation in $\mathrm{H}$-bonding of the hydrogen atoms of the C-3, C-4, and C- 6 hydroxyl groups. The methyl group of the 2-acetamido-2deoxy group also appears to be involved in non-covalent binding to the lectin, inasmuch as substitution of the $N$-acetyl group by an $N$-formyl group decreases binding by a factor of $1 / 3$.

One of the most interesting discoveries made in this study concerns linkage specificity (Tables III and IV). The data indicate that, among disaccharides containing $D$-glucose or 2-acetamido-2-deoxy-D-glucopyranose in the non-reducing position, the $\beta$ - $(1 \rightarrow 6)$-linked isomer is the poorest inhibitor. Thus, 6-O-(2-acetamido-2-deoxy$\beta$-D-glucopyranosyl)-D-galactopyranose is only one-tenth as active as its $\alpha$-D-linked isomer, and gentiobiose $[\beta-\mathrm{D}-\mathrm{Glc} p-(1 \rightarrow 6)-\mathrm{D}-\mathrm{Glc}]$ has only about $5 \%$ of the activity of isomaltose $[\alpha-D-G l c p-(1 \rightarrow 6)-D-G l c]$. These results are similar to those found by Osawa ${ }^{29}$ for the lectins from Laburnum alpinum and Cytisus sessifolius. Wood and coworkers classified both 6-O-(2-acetamido-2-deoxy- $\beta$-D-glucopyranosyl)-D-galactopyranose and 3-O-(2-acetamido-2-deoxy- $\beta$-D-glucopyranosyl)-D-galactopyranose as non-inhibitors ${ }^{5}$. We were able to obtain a somewhat more-accurate comparison between the $\alpha$ - and $\beta$-linked disaccharides because our hapten-inhibition system was approximately 10 times more sensitive than the BS II lectin-horse giycoprotein system used by Wood et al. It is also interesting that maltose and cellobiose (Table IV) inhibit BS II to the same extent as kojibiose which, in turn, is about half as active as sophorose.

The lectin of Bandeiraea simplicifolia II contrasts with concanavalin $A$ in interacting with both $\alpha$ - and $\beta$-linked 2-acetamido-2-deoxy-D-glucopyranosyl residues (concanavalin $A$ binds only the $\alpha$ anomer) and in its greater than 400 -fold preference for 2-acetamido-2-deoxy-D-glucopyranose over D-glucose (concanavalin A binds $D$-glucose approximately twice as avidly as the amino sugar) ${ }^{6,28,30}$. The BS II lectin also differs from wheat-germ agglutinin ${ }^{31}$ and the potato lectin ${ }^{32}$ in that it does not bind to internal, $\beta$ - $(1 \rightarrow 4)$-linked, 2-acetamido-2-deoxy-D-glucopyranosyl residues; nor does BS II appear to possess an extended binding-site for contiguous, $\beta$ - $(1 \rightarrow 4)$ linked 2-acetamido-2-deoxy-D-glucopyranosyl residues.

Used in conjunction with concanavalin $A$, we believe that BS $\Pi$ lectin will prove to be a useful probe for the detection and characterization of nonreducing, 
terminal 2-acetamido-2-deoxy-D-glucopyranosyl groups as they occur in polysaccharides, glycoproteins, and glycolipids.

ACKNOWLEDGMENT

This work was supported by USPHS grant no. AM-10171.

\section{REFERENCES}

1 C. C. Hayes and I. J. Goldstein, J. Biol. Chem., 249 (1974) 1904-1914.

2 P. N. Shankar Iyer, K. D. Wilkinson, and I. J. Goldsten, Arch. Biochem. Biophys., 177 (1976) 330-333.

3 L. A. Murphy and I. J. Goldsten, J. Biol. Chem., 252 (1977) 4739-4742.

4 W. J. Judd, M. L. Beck, B. L. Hrcklin, P. N. Shanker IYer, AND I. J. Goldstern, Vox Sang., 33 (1977) 246-251.

5 C. Wood, E. A. Kabat, S. Ebisu, ANd I. J. Goldstein, Ann. Immunol. (Paris), (1978), in press.

6 R. D. Poretz AND I. J. Goldstein, Biochemistry, 9 (1970) 2890-2896.

7 S. EBisu AND I. J. Goldstern, Methods Enzymol., 50 (1977) 350-354.

8 J. Janatova, J. K. Fuller, And M. J. Hunter, J. Biol. Chem., 243 (1968) 3612-3622.

9 L. L. So AND I. J. GoldsteIN, $J$. Biol. Chem., 242 (1967) 1617-1622.

10 G. Schiffman, C. Howe, AND E. A. Kabat, J. Am. Chem. Soc., 80 (1958) 6662-6670.

11 R. MAGe AND S. DaY, J. Immunol., 95 (1965) 525-535.

12 F. Karuse, J. Am. Chem. Soc., 78 (1956) 5519.5526.

13 G. S. HASSING AND I. J. GoldsteIn, Eur. J. Biochem., 16 (1970) 549-556.

14 F. G. Loontiens, J. P. Van Wauwe, R. De Gussen, and C. K. DeBruyne, Carbohydr. Res., 30 (1973) 51-62.

15 T. W. SHIER, Proc. Natl. Acad. Sci. USA, 68 (1971) 2078-2082.

16 S. Hammarström, E. EngVall, B. G. Johansson, S. Svensson, G. Sundblad, and I. J. Goldstein, Proc. Natl. Acad. Sci. USA, 72 (1975) 1528-1532.

17 B. Lindierg, J. Lönngren, And D. A. Powell, Carbohydr. Res., 58 (1977) 177-186.

18 S. Kotani, Y. Watanabe, T. ShImono, F. Kinoshita, T. Narita, K. Kato, D. E. S. StewartTULI, I. MORISAKT, K. YoKogaWA, AND S. KaWATA, Biken J., 18 (1975) 93-103.

19 R. G. SpIRo, J. Biol. Chem., 239 (1964) 567-573.

20 I. J. Goldstein, S. Hammarström, and G. Sundalad, Biochim. Biophys. Acta, 405 (1975) 53-61.

21 S. Egisu, J. LönNGRen, AND I. J. Goldstein, Carbohydr. Res., 58 (1977) 187-191.

22 R. Lotan, N. SHaron, AND D. Mirelman, Eur. J. Biochem., 55 (1975) 257-262.

22 H. E. Carlsson, J. LönNGRen, I. J. Goldstein, J. E. Christiner, AND G. W. Jourdian, FEBS Lett., 62 (1976) 38-40.

24 P. T. Mora, J. W. WOOd, and V. W. McFarland, J. Am. Chem. Soc., 81 (1960) 3418-3421.

25 W. Galbraith AND I. J. Goldstem, Biochemistry, 11 (1972) 3976-3984.

26 L. L. So AND I. J. GoldDSten, Carbohydr. Res., 10 (1969) 231-244.

27 G. Scatchard, Ann. N.Y. Acad. Sci., 51 (1949) 660-672.

28 I. J. Goldstein, C. M. Reichert, AND A. Misaki, Ann. N.Y. Acad. Sci., 234 (1974) 283-296.

29 T. OsAwa, Biochim. Biophys. Acta, 115 (1966) 507-510.

30 E. E. SMITH AND I. J. Goldstern, Arch. Biochem. Biophys., 121 (1967) 88-95.

31 A. K. AILEN, A. NEUBERGer, AND N. Sharon, Biochem. J., 131 (1973) 155-162.

32 A. K. Allen AND A. Neuberger, Biochem. J., 135 (1973) 307-314. 